\title{
Perfil de ácidos graxos do leite de vacas Holandês x Gir em pastagem de capim-marandu suplementado com quantidades crescentes de grão de soja tostado
}

\author{
[Milk fatty acid profile of Holstein x Gyr cows grazing on marandugrass supplemented \\ with increasing levels of roasted soybeans] \\ M.H.F. Mourthé ${ }^{1}$, R.B. Reis $^{2}$, M.A.S. Gama ${ }^{3}$, P.A.V. Barros $^{4}$, R. Antoniassi ${ }^{5}$, \\ H.R. Bizzo ${ }^{5}$, F.C.F. Lopes ${ }^{3}$ \\ ${ }^{1}$ Instituto de Ciências Agrárias - UFMG - Montes Claros, MG \\ ${ }^{2}$ Escola de Veterinária - UFMG - Belo Horizonte, MG \\ ${ }^{3}$ Embrapa Gado de Leite - Juiz de Fora, MG \\ ${ }^{4}$ Aluna de pós-graduação - Faculdade de Farmácia - UFMG - Belo Horizonte, MG \\ ${ }^{5}$ Embrapa Agroindústria de Alimentos - Rio de Janeiro, RJ
}

\begin{abstract}
RESUMO
O experimento foi realizado na Embrapa Gado de Leite, em delineamento quadrado latino (QL) 4x4, com o objetivo de avaliar o perfil de ácidos graxos (AG) e os índices de qualidade nutricional da gordura do leite de vacas Holandês x Gir $(\mathrm{n}=16)$ sob pastejo em Brachiaria brizantha cv. Marandu suplementada com concentrado (6kg/vaca/dia) contendo $0 ; 1,3 ; 2,6$ e 3,9kg (base matéria natural) de grão de soja tostado (GST). Foram observados decréscimos lineares $(\mathrm{P}<0,0001)$ nas concentrações e nas secreções dos AG láurico, mirístico e palmítico e dos AG de cadeia ímpar linear e ramificada, bem como incrementos lineares $(\mathrm{P}<0,0001)$ nas concentrações e secreções dos AG $\alpha$-linolênico, linoleico, oleico e esteárico na gordura do leite, com a inclusão do GST no concentrado. As concentrações e as secreções dos AG vacênico e rumênico apresentaram comportamento quadrático $(\mathrm{P}<0,001)$ em resposta à inclusão de quantidades crescentes de GST na dieta. As alterações observadas no perfil de AG do leite com o aumento da inclusão de GST no concentrado resultaram em reduções lineares $(\mathrm{P}<0,0001)$ nos índices de aterogenicidade e de trombogenicidade e em incrementos lineares $(\mathrm{P}<0,0001)$ nas relações entre AG hipo:hipercolesterolêmicos e entre AG $\omega-6: \omega-3$ da gordura do leite. Os resultados deste estudo mostraram que a inclusão de quantidades crescentes de GST na dieta de vacas Holandês x Gir pastejando capim-marandu apresenta potencial para a secreção de leite com gordura enriquecida com ácidos graxos benéficos à saúde humana.
\end{abstract}

Palavras-chave: ácido rumênico, ácido vacênico, aterogenicidade, Brachiaria, CLA

\begin{abstract}
The experiment was carried out at Embrapa Dairy Cattle in order to evaluate the milk fatty acid (FA) composition and indices of nutritional quality of milk fat from Holstein $x$ Gyr cows $(n=16)$ grazing on Brachiaria brizanta $c v$. Marandu supplemented with concentrate $(6 \mathrm{~kg} / \mathrm{cow} / \mathrm{d})$ containing 0, 1.3, 2.6 and $3.9 \mathrm{~kg}$ (as-fed basis) of roasted soybeans $(R S)$. A linear decrease $(P<0.0001)$ in the content and secretion of lauric, myristic and palmitic FA, and odd-and branched-chain FA was observed, whereas the content and secretion of $\alpha$-linolenic, linoleic, oleic, and stearic FA in milk fat increased linearly $(P<0.0001)$ as the amount of $R S$ increased in the diet. The milk fat content and secretion of vaccenic and rumenic FA increased quadratically $(P<0.001)$ in response to dietary $R S$ level. As a consequence of the above-mentioned changes in milk FA composition, both atherogeniticy and trombogenicity indices of milk fat were reduced linearly $(P<0.0001)$, whereas hypo:hypercholesterolemic and $\omega-6: \omega-3$ FA ratios increased linearly $(P<0.0001)$ in milk fat from cows fed increasing levels of RS. The results showed that dietary supplementation with increasing amounts of $R S$ have the potential to secrete fat milk enriched fatty acids beneficial to human health.
\end{abstract}

Keywords: atherogenicity, Brachiaria, CLA, rumenic acid, vaccenic acid

Recebido em 19 de março de 2014

Aceito em 4 de maio de 2015

E-mail: kikolider@yahoo.com.br 


\section{INTRODUÇÃO}

A fração lipídica do leite de ruminantes contém, naturalmente, ácidos graxos (AG) que apresentam efeitos benéficos à saúde humana, tais como: 1) ácido rumênico (CLA cis-9 trans11), com propriedades anticarcinogênicas, antidiabetogênicas e antiaterogênicas (Benjamin e Spener, 2009); 2) ácido vacênico (C18:1 trans11), precursor para síntese do ácido rumênico na glândula mamária de ruminantes (Shingfield et al., 2013) e nos tecidos de humanos (Turpeinen et al., 2002); 3) ácido oleico (C18:1 cis-9), que reduz a concentração da fração LDL do colesterol plasmático (FAO, 2010); e 4) ácido $\alpha$ linolênico (C18:3 cis-9 cis-12 cis-15), essencial ao metabolismo humano e precursor de outros AG da família $\omega-3$, aos quais se atribuem propriedades cardioprotetoras e antiinflamatórias (Salter, 2013). No entanto, a despeito dessas características, o consumo da gordura do leite presente em produtos lácteos full fat (e.g. leite integral) tem sido frequentemente associado ao maior risco de ocorrência de doenças cardiovasculares devido aos teores elevados dos AG saturados láurico (C12:0), mirístico (C14:0) e palmítico (C16:0), considerados hipercolesterolêmicos (Food..., 2010).

Sistemas de produção de leite baseados em pastagens formadas com gramíneas tropicais, especialmente quando suplementadas com óleos vegetais ricos em AG oleico, linoleico (C18:2 cis-9 cis-12) e/ou $\alpha$-linolênico (e.g. grão de soja tostado - GST), constituem estratégia promissora para se alterar positivamente o perfil de AG do leite tanto pela redução das concentrações dos AG láurico, mirístico e palmítico, quanto pelo concomitante incremento dos teores dos AG rumênico, vacênico e oleico (Lopes et al., 2011b). A despeito disso, são escassos os trabalhos sobre o tema.

Na literatura, há proposição de vários índices de qualidade nutricional da gordura baseados em relações entre concentrações de determinados AG saturados e insaturados, que podem complementar a avaliação do perfil de AG do leite (Barros et al., 2013).

Este estudo objetivou avaliar efeitos da inclusão de quantidades crescentes de grão de soja tostado no concentrado sobre o perfil de ácidos graxos e índices de qualidade nutricional da gordura do leite de vacas sob pastejo em capim-marandu.

\section{MATERIAL E MÉTODOS}

O trabalho foi realizado na Embrapa Gado de Leite (Coronel Pacheco, MG), de 6 de fevereiro a 10 de abril de 2009, e os procedimentos experimentais utilizados foram aprovados pelo Comitê de Ética em Experimentação Animal da Universidade Federal de Minas Gerais, Belo Horizonte, MG (Protocolo CETEA 196/08). Foram utilizadas 16 vacas Holandês $\mathrm{x}$ Gir, multíparas, com $58 \pm 20$ dias de lactação, produção de leite de $20 \pm 5 \mathrm{~kg} / \mathrm{dia}$ e $506 \pm 51 \mathrm{~kg}$ de peso vivo. Utilizou-se delineamento com quatro quadrados latinos (QLs) 4 x 4 contemporâneos, onde cada fase dos QLs compreendeu 15 dias (10 dias de adaptação às dietas e cinco de coletas), sendo as vacas alocadas nos QLs em função do grau de sangue, da produção de leite e dos dias em lactação. As vacas foram manejadas sob pastejo contínuo em 9ha de Brachiaria brizantha cv. Marandu, com oferta mínima de $153 \mathrm{~kg} / \mathrm{vaca} / \mathrm{dia}$ de pasto, que foi suplementada com quatro diferentes concentrados, que consistiram nos tratamentos experimentais. Os concentrados foram formulados com quantidades crescentes $(0 ; 1,3 ; 2,6$ e 3,9kg) de grão de soja tostado (GST), que parcialmente substituiu a energia proveniente do fubá de milho e da polpa cítrica e a proteína do farelo de soja. As composições centesimal e química dos concentrados foram relatadas por Mourthé et al. (2012). A quantidade diária de concentrado (6kg/vaca, base matéria natural) foi dividida em duas partes iguais fornecidas após as ordenhas da manhã (às seis horas) e da tarde (às 14h) em freestall, com cochos eletrônicos individuais do tipo calan-gate (American Calan Inc., Northewood, EUA). A tostagem foi realizada sob temperatura de 145 a $149^{\circ} \mathrm{C}$, por 30 a $45 \mathrm{~s}$, com $35 \mathrm{~min}$ de steeping. O GST foi moído em moinho com peneira com abertura de malhas de $10 \mathrm{~mm}$, antes de ser misturado aos concentrados, e apresentou $38,6 \%$ de proteína bruta e $22,3 \%$ de extrato etéreo (EE) na matéria seca (MS). No primeiro dia do período de adaptação de cada fase dos QLs, foram obtidas e congeladas a $-10^{\circ} \mathrm{C}$ amostras de extrusas da forragem selecionada na pastagem por uma vaca em lactação fistulada no esôfago. Amostras do GST também foram coletadas em cada fase dos QLs. Posteriormente, as amostras de extrusas e de GST foram liofilizadas, moídas $(1 \mathrm{~mm})$ e analisadas quanto 
ao perfil de $\mathrm{AG}$, por cromatografia em fase gasosa, conforme procedimentos descritos por Perez et al. (2010). No $11^{\circ}$ dia de cada fase dos QLs, foram coletadas em frascos sem conservantes amostras representativas da produção individual diária de leite (2/3 na ordenha da manhã $+1 / 3$ na ordenha da tarde), que foram congeladas a $-10^{\circ} \mathrm{C}$, visando analisar o perfil de $A G$, realizado por cromatografia em fase gasosa, segundo os procedimentos descritos por Baldin et al. (2013). Os índices de aterogenicidade (IA) e de trombogenicidade (IT) e as relações entre os AG ômega 6:ômega 3 ( $\omega$ 6:(-3) e AG hipo:hipercolesterolêmicos (h/H) foram utilizados para avaliar a qualidade nutricional da gordura do leite (Barros et al., 2013). Os resultados foram analisados por modelos mistos (procedimento MIXED do SAS, versão 9.0), sendo considerado efeito fixo o nível de GST no concentrado, e aleatórios, fase, vaca (QL) e QL. Utilizou-se o comando LSMEANS para a geração das médias das variáveis e respectivos erros-padrão. Os efeitos linear e quadrático foram analisados por contrastes ortogonais (comando CONTRAST), e as respectivas equações de regressão geradas pelo procedimento REG. Efeitos foram considerados significativos quando $\alpha=0,05$.

\section{RESULTADOS E DISCUSSÃO}

Os AG presentes em maiores concentrações na extrusa $(1,2 \%$ de EE) foram o AG linoleico e, principalmente, o $\alpha$-linolênico (Tab. 1), os mesmos AG relatados por O'Kelly e Reich (1976) em estudo com gramíneas tropicais, apresentando-se também dentro da variação relatada em pastos de Brachiaria (Fernandes et al., 2007). Esses dois AG, juntamente com o ácido oleico, são os principais substratos para formação, via rotas de bio-hidrogenação $(\mathrm{BH})$, do ácido vacênico no rúmen (Shingfield et al., 2010). Ressalta-se que 70 a $95 \%$ do ácido rumênico secretado no leite originam-se de síntese na glândula mamária, por meio da enzima estearoil-CoA dessaturase (SCD), que insere uma dupla ligação do tipo cis na posição 9 da cadeia carbônica do ácido vacênico (Shingfield et al., 2013). Quanto ao GST, os maiores teores foram para os AG linoleico e oleico (Tab. 1), semelhante aos relatados por Chouinard et al. (1997).

Tabela 1. Principais ácidos graxos presentes na extrusa do pasto de Brachiaria brizantha e no grão de soja tostado

\begin{tabular}{lcc}
\hline Ácido graxo (g/100 g de ácidos graxos totais) & $\begin{array}{c}\text { Extrusa do pasto } \\
\text { C12:0 (ácido láurico) }\end{array}$ & $\begin{array}{c}\text { Grão de soja } \\
\text { tostado }\end{array}$ \\
C14:0 (ácido mirístico) & 0,78 & 0,02 \\
C16:0 (ácido palmítico) & 0,49 & 0,07 \\
C16:1 cis-9 (ácido palmitoleico) & 23,5 & 11,4 \\
C18:0 (ácido esteárico) & 1,27 & 0,09 \\
C18:1 cis-9 (ácido oleico) & 3,04 & 3,40 \\
C18:2 cis-9 cis-12 (ácido linoleico) & 4,59 & 22,14 \\
C18:3 cis-9 cis-12 cis-15 (ácido $\alpha$-linolênico) & 19,7 & 53,2 \\
\hline
\end{tabular}

Foram observados decréscimos lineares $(\mathrm{P}<0,0001)$ nas concentrações dos AG saturados com número par de carbonos C4:0, C6:0, C8:0, C10:0, C12:0, C14:0 e C16:0 (Tab. 2) em resposta ao aumento da quantidade de GST na dieta. A síntese de novo na glândula mamária é responsável por 100\% dos AG C4:0, C6:0, C8:0, C10:0 e C12:0; aproximadamente $95 \%$ do C14:0; e 50\% do C16:0 secretados no leite (Shingfield et al., 2013). As reduções nos teores destes AG na gordura do leite podem ter sido ocasionadas por um ou mais dos seguintes fatores: 1) a inclusão do GST no concentrado das vacas inibiu a fermentação ruminal dos carboidratos fibrosos da dieta pela microbiota fibrolítica, resultando em menores concentrações plasmáticas de acetato e também de $\beta$-hidroxibutirato e, por conseguinte, reduzindo a síntese de novo de AG na glândula mamária (Shingfield et al., 2013); 2) a elevada concentração de AG insaturados de cadeia longa oriundos do GST inibiu a abundância de mRNAs e as atividades de enzimas relacionadas à síntese de novo de AG (acetil-CoA carboxilase e AG sintetase) na glândula mamária (Jayan, 1998); e 3) a elevada disponibilidade na glândula mamária de AG de cadeia longa e sua seletiva e preferencial incorporação nos triglicerídeos da gordura do leite em detrimento dos AG de 
cadeias saturadas curtas e médias promoveu efeito de substituição e limitou a secreção destes no leite. Outros autores também relataram reduções nas concentrações dos AG C12:0,
C14:0 e C16:0 do leite bovino quando dietas foram suplementadas com GST (Dhiman et al., 1995; Liu et al., 2008).

Tabela 2. Perfil de ácidos graxos na gordura do leite de vacas Holandês x Gir em pastagem de $B$. brizantha cv. Marandu suplementada com grão de soja tostado (GST)

\begin{tabular}{|c|c|c|c|c|c|c|c|}
\hline \multirow{2}{*}{$\begin{array}{l}\text { Ácido graxo (AG) } \\
\text { (g/100 de AG totais) }\end{array}$} & \multicolumn{4}{|c|}{$\begin{array}{l}\text { Quantidade de GST no } \\
\text { concentrado }(\mathrm{kg})\end{array}$} & \multirow{2}{*}{$\begin{array}{c}\text { Erro } \\
\text { padrão da } \\
\text { média }\end{array}$} & \multicolumn{2}{|c|}{ Efeito (valor de P) } \\
\hline & 0,0 & 1,3 & 2,6 & 3,9 & & Linear & Quadrático \\
\hline$\Sigma$ AG C4:0 + C6:0 + C8:0 + C10:0 & 9,21 & 8,51 & 7,85 & 7,22 & 0,2367 & $<0,0001$ & 0,7784 \\
\hline $\mathrm{C} 12: 0$ & 2,84 & 2,33 & 1,92 & 1,60 & 0,0778 & $<0,0001$ & 0,0427 \\
\hline $\mathrm{C} 14: 0$ & 10,57 & 8,86 & 7,66 & 6,44 & 0,1940 & $<0,0001$ & 0,0507 \\
\hline $\mathrm{C} 16: 0$ & 27,9 & 23,5 & 21,4 & 19,9 & 0,6344 & $<0,0001$ & $<0,0001$ \\
\hline$\Sigma \mathrm{AG} \mathrm{C} 12: 0+\mathrm{C} 14: 0+\mathrm{C} 16: 0$ & 41,3 & 34,6 & 31,0 & 27,9 & 0,7314 & $<0,0001$ & $<0,0001$ \\
\hline $\mathrm{C} 15: 0$ iso & 0,44 & 0,38 & 0,32 & 0,26 & 0,0134 & $<0,0001$ & 0,7683 \\
\hline $\mathrm{C} 15: 0$ anteiso & 0,68 & 0,60 & 0,52 & 0,45 & 0,0142 & $<0,0001$ & 0,7752 \\
\hline $\mathrm{C} 15: 0$ & 1,16 & 0,99 & 0,88 & 0,77 & 0,0216 & $<0,0001$ & 0,0194 \\
\hline $\mathrm{C} 17: 0$ & 0,55 & 0,50 & 0,46 & 0,43 & 0,0145 & $<0,0001$ & 0,2234 \\
\hline$\Sigma$ AG de cadeia ímpar linear ${ }^{1}$ & 2,35 & 2,03 & 1,78 & 1,58 & 0,0251 & $<0,0001$ & 0,0023 \\
\hline$\Sigma$ AG de cadeia ímpar e ramificada ${ }^{2}$ & 3,48 & 3,01 & 2,62 & 2,28 & 0,0472 & $<0,0001$ & 0,0384 \\
\hline C18:0 & 11,9 & 14,6 & 16,8 & 18,4 & 0,3148 & $<0,0001$ & 0,0176 \\
\hline C18:1 trans -4 & 0,019 & 0,029 & 0,035 & 0,036 & 0,0013 & $<0,0001$ & 0,0010 \\
\hline C18:1 trans -5 & 0,018 & 0,030 & 0,029 & 0,032 & 0,0037 & 0,0011 & 0,0718 \\
\hline C18:1 trans $6-8$ & 0,16 & 0,19 & 0,22 & 0,23 & 0,0067 & $<0,0001$ & 0,0054 \\
\hline C18:1 trans -9 & 0,25 & 0,28 & 0,31 & 0,32 & 0,0110 & $<0,0001$ & 0,0387 \\
\hline C18:1 trans -10 & 0,20 & 0,22 & 0,25 & 0,26 & 0,0127 & 0,0001 & 0,6596 \\
\hline C18:1 trans -11 & 2,19 & 2,40 & 2,57 & 2,34 & 0,1129 & 0,0135 & 0,0002 \\
\hline C18:1 trans -12 & 0,26 & 0,32 & 0,39 & 0,41 & 0,0132 & $<0,0001$ & 0,0033 \\
\hline C18:1 trans-13 e trans-14 & 0,30 & 0,32 & 0,33 & 0,35 & 0,0190 & 0,0161 & 0,7831 \\
\hline $\mathrm{C} 18: 1$ cis $-9+\mathrm{C} 18: 1$ trans -15 & 19,8 & 22,6 & 24,1 & 25,9 & 0,4393 & $<0,0001$ & 0,0185 \\
\hline C18:1 trans -16 & 0,24 & 0,34 & 0,35 & 0,38 & 0,0304 & 0,0003 & 0,1316 \\
\hline$\Sigma \mathrm{AG} \mathrm{C} 18: 1$ trans $^{3}$ & 3,63 & 4,15 & 4,48 & 4,35 & 0,1573 & $<0,0001$ & 0,0001 \\
\hline$\Sigma$ AG monoinsaturados cis de cadeia par ${ }^{4}$ & 23,8 & 26,4 & 27,6 & 29,3 & 0,4808 & $<0,0001$ & 0,0451 \\
\hline C18:2 cis-9 cis-12 ( $\omega-6)$ & 1,76 & 3,16 & 4,47 & 5,76 & 0,1855 & $<0,0001$ & 0,6747 \\
\hline $\mathrm{C} 20: 0$ & 0,15 & 0,16 & 0,18 & 0,18 & 0,0039 & $<0,0001$ & 0,0287 \\
\hline $\mathrm{C} 18: 3$ cis-9 cis-12 cis $-15(\omega-3)$ & 0,39 & 0,60 & 0,74 & 0,87 & 0,0253 & $<0,0001$ & 0,0190 \\
\hline CLA cis-9 trans -11 & 0,95 & 0,98 & 1,01 & 0,93 & 0,0517 & 0,8711 & 0,0092 \\
\hline CLA trans -9 cis -11 & 0,031 & 0,035 & 0,034 & 0,032 & 0,0018 & 0,8740 & 0,0817 \\
\hline CLA trans -10 cis-12 & 0,018 & 0,016 & 0,015 & 0,011 & 0,0020 & 0,0038 & 0,4261 \\
\hline $\mathrm{C} 20: 2$ cis-11 cis-14 ( $\omega-6)$ & 0,025 & 0,029 & 0,030 & 0,031 & 0,0011 & 0,0004 & 0,1759 \\
\hline $\mathrm{C} 22: 0$ & 0,064 & 0,073 & 0,077 & 0,078 & 0,0020 & $<0,0001$ & 0,0321 \\
\hline $\mathrm{C} 20: 3$ cis-8 cis-11 cis-14 ( $\omega-6)$ & 0,077 & 0,089 & 0,101 & 0,103 & 0,0031 & $<0,0001$ & 0,1127 \\
\hline $\mathrm{C} 20: 4$ cis -5 cis-8 cis-11 cis-14 ( $\omega-6)$ & 0,122 & 0,123 & 0,126 & 0,118 & 0,0064 & 0,5142 & 0,2670 \\
\hline $\mathrm{C} 24: 0$ & 0,101 & 0,102 & 0,093 & 0,089 & 0,0019 & $<0,0001$ & 0,1987 \\
\hline
\end{tabular}

${ }^{1} \Sigma$ AG de cadeia ímpar linear $=\mathrm{C} 11: 0+\mathrm{C} 13: 0+\mathrm{C} 15: 0+\mathrm{C} 17: 0+\mathrm{C} 17: 1$ cis-9 + C21:0; ${ }^{2} \Sigma$ AG de cadeia ímpar e ramificada $=\Sigma \mathrm{AG}$ de cadeia ímpar linear $+\mathrm{C} 15: 0$ iso $+\mathrm{C} 15: 0$ anteiso $;{ }^{3} \Sigma$ AG C18:1 trans $=\mathrm{C} 18: 1$ trans $-4+\mathrm{C} 18: 1$ trans $-5+\mathrm{C} 18: 1$ trans $6-8+\mathrm{C} 18: 1$ trans $-9+\mathrm{C} 18: 1$ trans $-10+\mathrm{C} 18: 1$ trans $-11+\mathrm{C} 18: 1$ trans $-12+\mathrm{C} 18: 1$ trans $-13 \mathrm{e}$ trans- $14+\mathrm{C} 18: 1$ trans $-16 ;{ }^{4} \Sigma$ AG monoins. cis de cadeia par $=\mathrm{C} 14: 1$ cis- $9+\mathrm{C} 16: 1$ cis $-9+\mathrm{C} 18: 1$ cis $-9+\mathrm{C} 18: 1$ cis$11+\mathrm{C} 18: 1$ cis- $12+\mathrm{C} 18: 1$ cis-13 + C20:1 cis-11.

As concentrações totais de $\mathrm{AG}$ ramificados (anteiso e iso) e lineares de cadeia ímpar na gordura do leite foram linearmente reduzidas $(\mathrm{P}<0,01)$ pela inclusão de GST nas dietas (Tab. 2), sugerindo algum grau de inibição na atividade e crescimento das bactérias celulolíticas e/ou amilolíticas no rúmen. Os AG de cadeia ímpar e ramificada (AGCIR) secretados no leite são originados, em sua maior parte, de AG sintetizados de novo e incorporados na membrana celular das bactérias ruminais, de forma que as concentrações desses $\mathrm{AG}$ na gordura do leite podem ser indicativas da atividade e do crescimento da população 
bacteriana no rúmen (Vlaeminck et al., 2006). Segundo estes autores, as bactérias celulolíticas contêm maiores concentrações de AG iso, enquanto as amilolíticas são ricas em AG anteiso e de cadeia linear ímpar. Os AGCIR encontrados em maiores concentrações na gordura do leite foram C15:0, C15:0 anteiso, C17:0 e C15:0 iso, cujos teores estão dentro das faixas de variação relatadas por Vlaeminck et al. (2006).

As concentrações dos AG $\alpha$-linolênico, linoleico e oleico na gordura do leite aumentaram linearmente $(\mathrm{P}<0,0001)$ com a inclusão do GST no concentrado (Tab. 2), indicando que a tostagem do grão de soja promoveu, em alguma extensão, proteção do óleo no rúmen, reduzindo sua liberação e, por conseguinte, a BH desses AG, disponibilizando-os para absorção intestinal e captação pela glândula mamária para secreção no leite (Dhiman et al., 1995; Liu et al., 2008). Considerando esse aspecto, pressupõe-se que o impacto negativo da presença de AG insaturados do óleo do GST na microbiota ruminal, em especial sobre a atividade e o crescimento das bactérias celulolíticas, não foi $o$ principal responsável pelas reduções lineares $(\mathrm{P}<0,0001)$ nas concentrações de AG saturados $\mathrm{C} 4: 0$ a C16:0 na gordura do leite (Tab. 2). Corroborando essa hipótese, houve incremento linear $(\mathrm{P}<0,0001)$ na concentração de ácido esteárico (C18:0) na gordura do leite, com $55 \%$ de aumento no teor deste AG no tratamento com 3,9kg de GST em relação ao controle (Tab. 2). Os teores de C18:0 na gordura do leite das vacas que receberam GST variaram de 14,6 a $18,4 \mathrm{~g} / 100 \mathrm{~g}$ de $\mathrm{AG}$ totais (Tab. 2), sendo superiores ao relatado por Lopes et al. (2011a), de 11,4g/100g de AG totais, no leite de vacas Holandês em pastagem de $B$. brizantha cv. Xaraés suplementada com $6 \mathrm{~kg} / \mathrm{dia}$ de concentrado sem ingredientes ricos em AG. Esses elevados teores de C18:0 no leite parcialmente indicaram que a microbiota envolvida nos processos de $\mathrm{BH}$ dos $\mathrm{AG}$ insaturados encontrou ambiente ruminal que não limitou sua atividade. Outros autores também relataram aumento do teor de C18:0 na gordura do leite de vacas recebendo dietas com GST (Dhiman et al., 1995; Liu et al., 2008). Por outro lado, observou-se que, mesmo com a redução linear $(\mathrm{P}<0,0001)$ da relação produto:substrato da SCD para o par AG C18:1 cis-9:C18:0 (Tab. 3) que, segundo Shingfield et al. (2013), é responsável pela secreção de aproximadamente $60 \%$ do ácido oleico no leite, os incrementos lineares $(\mathrm{P}<0,0001)$ na concentração e secreção deste AG, bem como dos AG $\alpha$-linolênico e linoleico na gordura do leite (Tab. 2 e 3), indicam elevada eficiência de transferência destes AG da dieta para o leite (Dhiman et al., 1995).

Tabela 3. Índices da atividade (relações produto:substrato) da enzima estearoil-CoA dessaturase na gordura do leite de vacas Holandês x Gir em pastagem de Brachiaria brizantha cv. Marandu suplementada com grão de soja tostado (GST)

\begin{tabular}{|c|c|c|c|c|c|c|c|}
\hline \multirow[b]{2}{*}{ Índices ${ }^{1}$} & \multicolumn{4}{|c|}{ Quantidade de GST no concentrado (kg) } & \multirow{2}{*}{$\begin{array}{c}\text { Erro padrão } \\
\text { da média }\end{array}$} & \multicolumn{2}{|c|}{ Efeito (valor de P) } \\
\hline & 0,0 & 1,3 & 2,6 & 3,9 & & Linear & Quadrático \\
\hline $\mathrm{C} 14: 1$ cis-9/(C14:0 + C14:1 cis-9) & 0,0811 & 0,0732 & 0,0669 & 0,0624 & 0,0038 & $<0,0001$ & 0,1671 \\
\hline $\mathrm{C} 16: 1$ cis-9/(C16:0 + C16:1 cis-9) & 0,0439 & 0,0410 & 0,0366 & 0,0356 & 0,0016 & $<0,0001$ & 0,1893 \\
\hline $\mathrm{C} 18: 1$ cis-9/(C18:0 + C18:1 cis-9) & 0,6246 & 0,6083 & 0,5900 & 0,5845 & 0,0063 & $<0,0001$ & 0,3733 \\
\hline Rumênico/(rumênico + vacênico) & 0,2999 & 0,2906 & 0,2837 & 0,2871 & 0,0070 & 0,0047 & 0,0699 \\
\hline
\end{tabular}

determinados conforme descrito por Baldin et al. (2013).

As concentrações dos AG $\alpha$-linolênico, linoleico e oleico na gordura do leite das vacas que receberam GST (Tab. 2) foram bastante superiores às relatadas por Lopes et al. (2011a) no leite de vacas em pastagem de $B$. brizantha cv. Xaraés suplementada com $6 \mathrm{~kg} / \mathrm{dia}$ de concentrado sem ingredientes ricos nesses AG. Isto indica que, de fato, no presente trabalho, a provável elevação da concentração plasmática desses AG, bem como de outros AG insaturados de cadeia longa, conforme observaram Liu et al. (2008) em dietas com $1,42 \mathrm{~kg} /$ dia de GST, promoveu incremento na sua disponibilidade para captação pela glândula mamária. Isto, presumivelmente, promoveu inibição de enzimas relacionadas à síntese de novo de AG na glândula mamária (Jayan, 1998) e/ou resultou na sua preferencial incorporação nos triglicerídeos da gordura do leite em detrimento dos $\mathrm{AG}$ de cadeias saturadas curtas e médias, cujas secreções no leite foram linearmente reduzidas ( $\mathrm{P}<0,001 ;$ Tab. 4). As secreções dos AG esteárico, oleico, linoleico e $\alpha$-linolênico no leite foram linearmente aumentadas $(\mathrm{P}<0,0001) \mathrm{em}$ 
resposta à inclusão de GST no concentrado, enquanto as secreções dos ácidos rumênico e vacênico apresentaram comportamento quadrático $(\mathrm{P}<0,04)$. Por outro lado, foram observados decréscimos lineares nas secreções dos AGCIR $(\mathrm{P}<0,0001)$ e do CLA trans-10 cis$12(\mathrm{P}=0,0333)$ (Tab. 4). Todos esses resultados foram em razão das associações observadas entre as concentrações destes AG e a suplementação com GST (Tab. 2). As taxas de secreção $(\mathrm{P}<0,0001)$ dos $\mathrm{AG}$ com cadeia $\leq 16 \mathrm{C}(\hat{\mathrm{y}}=$ $\left.343,3-21,6^{*} x ; r^{2}=0,27\right)$ e dos AG de cadeia longa $\left(\geq 18 \mathrm{C} ; \hat{\mathrm{y}}=276,6+39,8 * x ; \mathrm{r}^{2}=0,56\right)$ foram, respectivamente, de $-21,6$ e $39,8 \mathrm{~g}$ de AG/kg de GST no concentrado, demonstrando a preferencial incorporação na gordura do leite de AG pré-formados ( $\geq 18 \mathrm{C})$ em detrimento daqueles sintetizados de novo. Esse efeito de substituição pode ser também observado pela redução linear $(\mathrm{P}<0,0001)$ na razão $\Sigma \mathrm{AG} \leq 16$ $\mathrm{C} / \Sigma \mathrm{AG} \geq 18 \mathrm{C}$ (Tab. 4).

Tabela 4. Secreções de ácidos graxos no leite de vacas Holandês x Gir em pastagem de Brachiaria brizantha cv. Marandu suplementada com grão de soja tostado (GST)

\begin{tabular}{|c|c|c|c|c|c|c|c|}
\hline \multirow[b]{2}{*}{ Secreção de ácido graxo - AG (g/dia) ${ }^{1}$} & \multicolumn{4}{|c|}{ Quantidade GST no concentrado $(\mathrm{kg})$} & \multirow{2}{*}{$\begin{array}{c}\text { Erro } \\
\text { padrão da } \\
\text { média }\end{array}$} & \multicolumn{2}{|c|}{ Efeito (valor de P) } \\
\hline & 0 & 1,3 & 2,6 & 3,9 & & Linear & Quadrático \\
\hline$\Sigma$ AG C4:0 + C6:0 + C8:0 + C10:0 & 60,1 & 60,0 & 55,9 & 51,7 & 3,0615 & 0,0002 & 0,2163 \\
\hline $\mathrm{C} 12: 0$ & 18,6 & 16,5 & 13,7 & 11,4 & 0,8919 & $<0,0001$ & 0,9053 \\
\hline C14:0 & 69,1 & 62,4 & 54,5 & 46,2 & 2,8815 & $<0,0001$ & 0,6154 \\
\hline C16:0 & 181,8 & 163,9 & 152,3 & 142,2 & 7,3749 & $<0,0001$ & 0,3190 \\
\hline$\Sigma$ AG C12:0 + C14:0 + C16:0 & 269,5 & 242,9 & 220,5 & 199,9 & 10,5168 & $<0,0001$ & 0,6058 \\
\hline C18:0 & 77,5 & 101,8 & 119,5 & 131,6 & 5,6718 & $<0,0001$ & 0,0897 \\
\hline C18:1 trans -11 & 14,2 & 16,8 & 18,3 & 16,7 & 1,1347 & 0,0006 & 0,0003 \\
\hline $\mathrm{C} 18: 1$ cis $-9+\mathrm{C} 18: 1$ trans -15 & 128,6 & 158,5 & 171,0 & 185,3 & 9,0292 & $<0,0001$ & 0,0768 \\
\hline C18:2 cis-9 cis-12 & 11,3 & 22,1 & 31,7 & 41,1 & 1,6241 & $<0,0001$ & 0,5679 \\
\hline C18:3 cis -9 cis -12 cis -15 & 2,5 & 4,2 & 5,2 & 6,2 & 0,2250 & $<0,0001$ & 0,0607 \\
\hline CLA cis -9 trans -11 & 6,1 & 6,9 & 7,2 & 6,6 & 0,4946 & 0,0301 & 0,0009 \\
\hline CLA trans -9 cis -11 & 0,203 & 0,244 & 0,245 & 0,225 & 0,0255 & 0,2906 & 0,0202 \\
\hline CLA trans -10 cis- 12 & 0,111 & 0,109 & 0,107 & 0,076 & 0,0140 & 0,0333 & 0,2053 \\
\hline$\Sigma$ AG de cadeia ímpar e ramificada (AGCIR $)^{2}$ & 22,6 & 21,1 & 18,7 & 16,3 & 1,0112 & $<0,0001$ & 0,3924 \\
\hline$\Sigma \mathrm{AG} \leq 16$ carbonos $/ \Sigma \mathrm{AG} \geq 18$ carbonos & 1,29 & 0,92 & 0,74 & 0,62 & 0,0248 & $<0,0001$ & $<0,0001$ \\
\hline
\end{tabular}

${ }^{1}$ Secreção $=$ (produção de leite, $\left.\mathrm{kg} / \mathrm{dia}\right) *($ teor de gordura no leite, \%)*0,93*(teor do AG na gordura do leite, g/100g de AG totais), em que 0,93 refere-se ao teor médio de AG na gordura do leite; ${ }^{2} \Sigma$ AGCIR $=\Sigma$ AG de cadeia ímpar linear $+\mathrm{C} 15: 0$ iso $+\mathrm{C} 15: 0$ anteiso.

Os resultados de desempenho produtivo do presente trabalho foram apresentados no artigo de Mourthé et al. (2012), no qual foi relatado que houve decréscimos lineares $(\mathrm{P}<0,05)$ nos consumos estimados de pasto, bem como nos consumos totais dos AG $\alpha$-linolênico, linoleico e oleico, em resposta à inclusão de quantidades crescentes de GST no concentrado. No rúmen, após a lipólise dos glico e fosfolipídeos presentes no pasto, e dos triglicerídeos dos grãos de oleaginosas consumidos pelo ruminante, ocorre liberação dos AG insaturados que, em sua forma livre, são o principal substrato para a microbiota em diversas rotas de $\mathrm{BH}$ ruminal (Buccioni et al., 2012). O produto final comum nessas rotas é o ácido esteárico, sendo encontrados como principais intermediários os AG C18:1 trans 616, C18:1 cis 10-15, além de isômeros conjugados (e.g. CLA cis-9 trans-11, CLA trans9 cis-11 e CLA trans-10 cis-12) e não conjugados do ácido linoleico (Shingfield et al., 2010; Buccioni et al., 2012). Exceto pelo teor do ácido vacênico, que apresentou comportamento quadrático $(\mathrm{P}=0,0002)$, foi observado incremento linear $(\mathrm{P}<0,05)$ nos teores dos demais AG C18:1 trans na gordura do leite, em resposta à inclusão de GST (Tab. 2). No entanto, os teores dos AG C18:1 trans na gordura do leite das vacas que receberam GST na dieta podem ser, de modo geral, considerados baixos (Lopes et al., 2011a). Essas baixas concentrações dos AG C18:1 trans na gordura do leite são indicativas do efeito de proteção do óleo do grão de soja promovido pela tostagem. Conforme observado para o ácido vacênico, também a concentração do ácido rumênico na gordura do leite apresentou comportamento quadrático $(\mathrm{P}=0,0092) \mathrm{em}$ resposta à inclusão crescente de GST na dieta (Tab. 2). Tal resultado corrobora a informação de que 70 a $95 \%$ do ácido rumênico secretado no 
leite originam-se do ácido vacênico, pela ação da enzima SCD na glândula mamária (Shingfield et al., 2013). A regressão dos teores dos AG rumênico $(\mathrm{y})$ versus vacênico $(\mathrm{x})$ demonstra essa estreita associação $\left(\hat{y}=0,18926+0,32842 * x ; r^{2}\right.$ $=0,70 ; \mathrm{P}<0,0001)$, também relatada por Liu et al. (2008). As máximas concentrações e secreções dos ácidos rumênico $(1,01 \mathrm{~g} / 100 \mathrm{~g}$ de AG totais e $7,5 \mathrm{~g} / \mathrm{dia})$ e vacênico $(2,52 \mathrm{~g} / 100 \mathrm{~g}$ de AG totais e $18 \mathrm{~g} / \mathrm{dia}$ ) na gordura do leite foram estimadas, respectivamente, quando 1,9 e $2,3 \mathrm{~kg}$; e 2,3 e $2,5 \mathrm{~kg}$ de GST foram incluídos no concentrado. É provável que, neste intervalo de inclusão de GST (1,9 a 2,5kg), houve maior aporte dietético dos AG $\alpha$-linolênico e linoleico metabolizáveis no rúmen, reflexo da redução linear $(\mathrm{P}<0,05)$ do consumo de pasto rico nestes AG (Tab. 1) em razão do incremento de GST no concentrado (Mourthé et al., 2012), bem como do consumo per se de quantidades crescentes de GST que, embora contendo elevado teor de ácido linoleico (Tab. 1), sua metabolizabilidade no rúmen foi, provavelmente, muito baixa.

Foi observado decréscimo linear $(\mathrm{P}=0,0034)$ na razão entre os AG rumênico e vacênico (Tab. 3) na gordura do leite, um dos pares utilizados como índice de atividade da SCD na glândula mamária. Isto pode estar associado à diferencial disponibilidade e captação destes AG pela glândula mamária em razção da dieta final consumida (pasto + concentrado) (Shingfield et al., 2010). Em estudo in vitro com células bovinas, Jayan (1998) observou que maiores concentrações dos ácidos rumênico e vacênico promoveram aumento na abundância de mRNA, bem como na atividade da enzima SCD, enquanto incrementos nos teores dos AG oleico e linoleico provocaram efeito inverso. Pelos teores dos AG oleico e linoleico na gordura do leite (Tab. 2), pressupõe-se que estes também estivessem elevados no plasma, bem como na glândula mamária. Em comparação com uma dieta sem inclusão de GST, a suplementação com $1,42 \mathrm{~kg} / \mathrm{dia}$ de GST resultou em incremento $(\mathrm{P}<0,05)$ nos teores dos AG linoleico e vacênico no plasma e no leite de vacas (Liu et al., 2008). Diversos trabalhos têm atribuído ao ácido rumênico propriedades anticarcinogênicas, antidiabetogênicas e antiaterogênicas (Benjamin e Spener, 2009). Além disso, aproximadamente $19 \%$ do ácido vacênico consumido podem ser metabolizados a ácido rumênico no organismo humano (Turpeinen et al., 2002). No presente estudo, as concentrações dos AG vacênico e rumênico (Tab. 2) podem ser consideradas elevadas quando comparadas aos teores médios (0,42 e 1,91g/100g de AG, respectivamente), calculados de resultados compilados por Lopes $e t$ al. (2011b), no leite de vacas recebendo dietas típicas de confinamento, baseadas em silagem de milho, feno e concentrados. Isto, mais uma vez, ilustra o potencial das gramíneas tropicais manejadas a pasto na produção de leite com gordura naturalmente enriquecida com AG benéficos à saúde humana. Foi observado decréscimo linear $(P=0,0038)$ na concentração de CLA trans-10 cis-12, e não houve efeito (P>0,05) sobre o teor do CLA trans-9 cis-11 em resposta à suplementação do pasto com quantidades crescentes de GST (Tab. 2). Esses dois isômeros de CLA são gerados no rúmen a partir de reações de BH parcial do ácido linoleico (Buccioni et al., 2012), e seus teores na gordura do leite são associados à depressão da gordura do leite (Shingfield et al., 2010). As regressões entre o teor de gordura no leite versus os teores desses dois CLAs não foram significativas ( $\mathrm{P}>0,05$; dados não apresentados), condizente com a ausência de efeito $(\mathrm{P}>0,05)$ da suplementação com quantidades crescentes de GST sobre a secreção ou o teor de gordura no leite (Mourthé et al., 2012). Ademais, não se esperaria redução no $\mathrm{pH}$ ruminal que favorecesse alguma mudança de rota de $\mathrm{BH}$ do ácido linoleico e, por consequência, incremento no teor do CLA trans$10 \mathrm{cis}-12$ na gordura do leite (Shingfield et al., 2010), haja vista que houve decréscimo linear $(\mathrm{P}<0,05)$ no consumo total de carboidratos não fibrosos com a inclusão de quantidades crescentes de GST na dieta (Mourthé et al., 2012).

Houve redução linear $(\mathrm{P}<0,0001)$ no IA e no IT e incremento linear $(\mathrm{P}<0,0001)$ na relação $\mathrm{h} / \mathrm{H}$ da gordura do leite com o aumento da inclusão de GST no concentrado (Tab. 5). 
Tabela 5. Índices de qualidade nutricional da gordura do leite de vacas em pastagem de Brachiaria brizantha $\mathrm{cv}$. Marandu suplementada com grão de soja tostado (GST)

\begin{tabular}{|c|c|c|c|c|c|c|c|}
\hline \multirow{2}{*}{ Índices ${ }^{1}$} & \multicolumn{4}{|c|}{$\begin{array}{l}\text { Quantidade de GST no } \\
\text { concentrado }(\mathrm{kg})\end{array}$} & \multirow{2}{*}{$\begin{array}{l}\text { Erro } \\
\text { padrão da } \\
\text { média }\end{array}$} & \multicolumn{2}{|c|}{ Efeito (valor de P) } \\
\hline & 0,0 & 1,3 & 2,6 & 3,9 & & Linear & Quadrático \\
\hline Relação ácidos graxos (AG) $\omega-6: \omega-3$ & 5,13 & 5,75 & 6,39 & 6,92 & 0,1789 & $<0,0001$ & 0,6342 \\
\hline $\begin{array}{l}\text { Relação AG } \\
\text { hipo:hipercolesterolêmicos }(\mathrm{h} / \mathrm{H})\end{array}$ & 0,49 & 0,68 & 0,81 & 0,97 & 0,0300 & $<0,0001$ & 0,3990 \\
\hline Índice de aterogenicidade (IA) & 3,30 & 2,31 & 1,84 & 1,45 & 0,0658 & $<0,0001$ & $<0,0001$ \\
\hline Índice de trombogenicidade (IT) & 4,12 & 3,14 & 2,75 & 2,40 & 0,0903 & $<0,0001$ & $<0,0001$ \\
\hline
\end{tabular}

${ }^{1}$ Equações: $\omega-6: \omega-3=\Sigma$ AG $\omega-6$ cis $/ \Sigma$ AG $\omega-3$ cis; $\mathrm{h} / \mathrm{H}=(\mathrm{C} 18: 1$ cis-9 + $\Sigma$ AG $\omega-3$ cis $) /(\mathrm{C} 12: 0+\mathrm{C} 14: 0+\mathrm{C} 16: 0)$; IA $=[\mathrm{C} 12: 0+(4 * \mathrm{C} 14: 0)+\mathrm{C} 16: 0] /(\mathrm{C} 18: 1$ cis $-9+\Sigma \mathrm{AG} \omega-6$ cis $+\Sigma \mathrm{AG} \omega-3$ cis $) ;$ e IT $=(\mathrm{C} 14: 0+\mathrm{C} 16: 0+$ $\mathrm{C} 18: 0) /\left[\left(0,5^{*} \mathrm{C} 18: 1\right.\right.$ cis-9) $+\left(0,5^{*} \Sigma \mathrm{AG} \omega-6\right.$ cis $)+\left(3^{*} \Sigma \mathrm{AG} \omega-3\right.$ cis $)+(\Sigma \mathrm{AG} \omega-3$ cis $/ \Sigma$ AG $\omega-6$ cis $\left.)\right]$, em que $\Sigma$ AG $\omega-6$ cis $=\mathrm{C} 18: 2$ cis -9 cis- $12+\mathrm{C} 20: 2$ cis- 11 cis- $14+\mathrm{C} 20: 3$ cis-8 cis-11 cis-14 + C20:4 cis-5 cis-8 cis-11 cis-14; e $\Sigma$ AG $\omega-3$ cis $=\alpha-\mathrm{C} 18: 3$ cis- 6 cis -9 cis- 12 .

A melhoria na qualidade nutricional da gordura do leite em resposta à suplementação com GST, demonstrada por estes três índices, pode ser principalmente atribuída à mudança no perfil de AG promovida pelo decréscimo nos teores dos AG láurico, mirístico e palmítico e pelo concomitante aumento nos dos AG oleico e $\alpha$ linolênico ( $\omega-3)$, bem como, especificamente considerando IA e IT, também nos dos AGPI $\omega$ 6 de configuração cis (Tab. 2). Segundo a Food... (2010), há evidência científica suficiente demonstrando que substituir AG de cadeia saturada por AGPI promove redução na concentração plasmática de LDL e na relação colesterol total/colesterol-HDL, respostas estas indicativas de menor risco de ocorrência de doenças cardiovasculares (CVD). Similar efeito cardioprotetor, embora em menor escala, pode ser obtido pela substituição dietética dos AG láurico, mirístico e palmítico por ácido oleico (Food..., 2010). As mudanças nos perfis de AG da gordura do leite em resposta ao incremento de GST no concentrado (Tab. 2) estão alinhadas com tais recomendações. Como o ácido esteárico apresenta comportamento de neutralidade na modulação da concentração plasmática de LDL (Food..., 2010), o incremento linear $(\mathrm{P}<0,0001)$ de seu teor na gordura do leite em razão da suplementação do pasto com GST (Tab. 2) pode ser considerado inócuo no aumento do risco de CVD. O incremento linear $(\mathrm{P}<0,0001)$ na relação AG $\omega-6: \omega-3$ em resposta à suplementação do pasto com quantidades crescentes de GST (Tab. 5) pode ser principalmente atribuído ao relativo maior aumento no teor do ácido linoleico $\left(\hat{y}=1,79+1,02 * x ; r^{2}=0,83 ; P<0,0001\right)$ em comparação com o do ácido $\alpha$-linolênico $\left(\hat{y}=0,41+0,12 * x ; r^{2}=0,82 ; \mathrm{P}<0,0001\right)$ na gordura do leite. Estes dois AG são dieteticamente essenciais, pois não são sintetizados no organismo humano (Food..., 2010) e são os principais AG das famílias $\omega-6$ e $\omega-3$ presentes no leite. À luz da atual limitação conceitual e da falta de consenso científico acerca da real utilidade da relação $\omega-6: \omega-3$ como métrica para recomendações dietéticas, sua relevância clínica como fator de risco associado à CVD tem sido questionada (Harris, 2006; Salter, 2013). Segundo Harris (2006), não há evidência científica de que a redução no consumo de AG $\omega-6$ e, por conseguinte, a "melhoria" na relação $\omega-6: \omega-3$ irão minimizar o risco de ocorrência de CVD. Por essa razão, Salter (2013) considerou imprudente recomendar redução no consumo de ácido linoleico simplesmente com o objetivo de atingir determinado valor numérico na relação $\omega-6: \omega-3$.

\section{CONCLUSÕES}

A inclusão de quantidades crescentes de grão de soja tostado na dieta de vacas Holandês x Gir pastejando capim-marandu apresenta potencial para a secreção de leite com gordura naturalmente enriquecida com ácidos graxos benéficos à saúde humana e com menores teores de ácidos graxos hipercolesterolêmicos. 


\section{AGRADECIMENTOS}

À Embrapa e à Fundação de Amparo à Pesquisa do Estado de Minas Gerais (Fapemig), pelo apoio financeiro ao trabalho.

\section{REFERÊNCIAS}

BALDIN, M.; GAMA, M.A.S.; DRESCH, R. et al. A rumen unprotected conjugated linoleic acid supplement inhibits milk fat synthesis and improves energy balance in lactating goats. J. Anim. Sci., v.91, p.3305-3314, 2013.

BARROS, P.A.V.; GLÓRIA, M.B.A.; LOPES, F.C.F. et al. Nutritional quality and oxidative stability of butter obtained from cows fed sugar-cane supplemented with sunflower oil. Arq. Bras. Med. Vet. Zootec., v.65, p.1545-1553, 2013.

BENJAMIN, S.; SPENER, F. Conjugated linoleic acids as functional food: an insight into their health benefits. Nutr. Metab., v.6, p.36-48, 2009.

BUCCIONI, A.; DECANDIA, M.; MINIERI, S. et al. Lipid metabolism in the rumen: New insights on lipolysis and biohydrogenation with an emphasis on the role of endogenous plant factors. Anim. Feed Sci. Technol., v.174, p.1-25, 2012.

CHOUINARD, P.Y.; GIRARD, V.; BRISSON, G.J. Performance and profile of milk fatty acids of cows fed full fat, heat-treated soybeans using various processing methods. J. Dairy Sci., v.80, p.334-342, 1997.

DHIMAN, T.R.; ZANTEN, K.V.; SATTER L.D. Effect of dietary fat source on fatty acid composition of cow's milk. J. Sci. Food Agric., v.69, p.101-107, 1995.

FATS and fatty acids in human nutrition. Report of an expert consultation. FAO Food Nutr. Pap., v.91, p. 99$119,2010$.

FERNANDES, S.A.A.; MATTOS, W.R.S; MATARAZZO, S.V. et al. Perfil de ácidos graxos em alimentos de clima tropical utilizados nas dietas para ruminantes. Bol. Ind. Anim., v.64, p.19-27, 2007.

HARRIS, W.S. The omega-6/omega-3 ratio and cardiovascular disease risk: uses and abuses. Curr. Atheroscler. Rep., v.8, p.453-459, 2006.

JAYAN, J.C. Activity and mRNA abundance of enzymes for fatty acid synthesis and desaturation in mammary cell cultures. 1998. nf. Dissertation (Doctor of Philosophy) - Virginia Polytechnic Institute and State University, Blacksburg, USA.
LIU, Z.L.; YANG, D.P.; CHEN, P. et al. Effect of dietary sources of roasted oilseeds on blood parameters and milk fatty acid composition. Czech. J. Anim. Sci., v.53, p.219-226, 2008.

LOPES, F.C.F.; BARROS, P.A.V.; BRUSCHI, J.H. et al. Milk fatty acids profile of Holstein cows grazing tropical forages supplemented with two concentrate levels. Arq. Bras. Med. Vet. Zootec., v.63, p.518-521, 2011a.

LOPES, F.C.F.; GAMA, M.A.S.; RIBEIRO, C.G.S. et al. Produção de leite com alto teor de CLA: experiência brasileira. In: PEREIRA, L.G.R.; NOBRE, M.M. et al. (Org.). Pesquisa, desenvolvimento $e$ inovação para sustentabilidade da bovinocultura leiteira. Juiz de Fora, MG: Embrapa Gado de Leite, 2011b, p.251-296.

MOURTHÉ, M.H.F.; REIS, R.B.; LOPES, F.C.F. et al. Performance milk composition and blood metabolites of Holstein x Gir cows grazing Brachiaria brizantha $\mathrm{cv}$. Marandu grass supplemented of roasted soybeans. Arq. Bras. Med. Vet. Zootec., v.64, p.1223$1231,2012$.

O' KELLY, J.C.; REICH, H.P. The fatty-acid composition of tropical pastures. J. Agric. Sci., v.86, p.427-429, 1976.

PEREZ, J.B.; SOUZA, R.S.C.; ANTONIASSI, R. et al. Perfil de ácidos graxos em cultivares de capim elefante utilizados na alimentação de vacas leiteiras. In: REUNIÃO ANUAL DA SOCIEDADE BRASILEIRA DE QUÍMICA, 2010, Águas de Lindoia, SP. Anais... São Paulo: Sociedade Brasileira de Química, 2010.

SALTER, A.M. Dietary fatty acids and cardiovascular disease. Animal, v.7, p.163-171, 2013.

SHINGFIELD, K.J.; BERNARD, L.; LEROUX, C.; CHILLIARD, Y. Role of trans fatty acids in the nutritional regulation of mammary lipogenesis in ruminants. Animal, v.4, p.1140-1166, 2010.

SHINGFIELD, K.J.; BONNET, M.; SCOLLAN, N.D. Recent developments in altering the fatty acid composition of ruminant-derived foods. Animal, v.7, p.132-162, 2013.

TURPEINEN, A.M; MUTANEN, M; ARO, A. et al. Bioconversion of vaccenic acid to conjugated linoleic acid in Humans. Am.. J. Clin. Nut., v.76, p.504-510, 2002.

VLAEMINCK, B.; FIEVEZ, V.; TAMMINGA, S. et al. Milk odd- and branched-chain fatty acids in relation to the rumen fermentation pattern. J. Dairy Sci., v.89, p.3954-3964, 2006. 